\title{
$\mathfrak{T} n$
}

\section{Sharmacentifde 3eitung}

\section{oed}

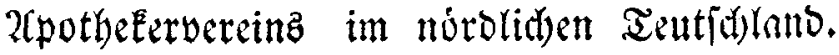

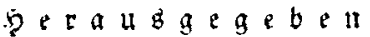

von

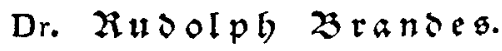

$D_{\text {ie grofe }}$ Berbreitung uno oab crfolgreitite $\mathfrak{B}$ irfent

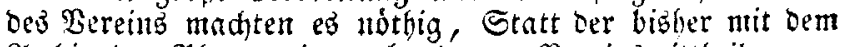

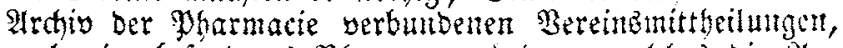

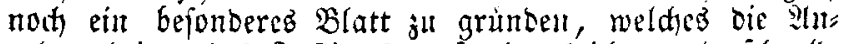

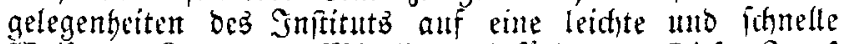

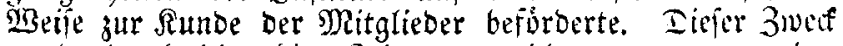
wurde curdh bie obige 3eitung erreicht, wovon mun ber

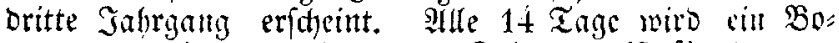

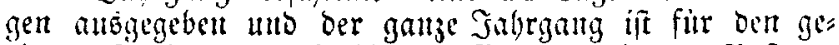

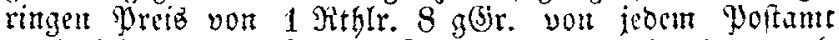

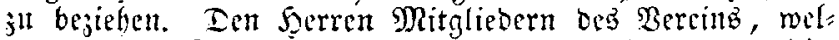
the an ber Entwictelung uno ber Servolfomment bies

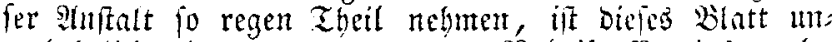
entbefrlid, indem ea, unter ber Rubrif: Siereinärngete:

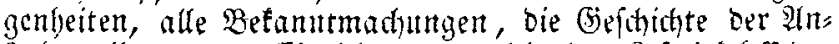
fralt, ibre nenen Einridhtungen, bie Der Rejegirtel, "wer

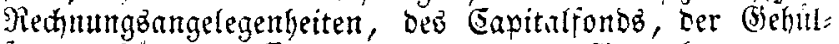

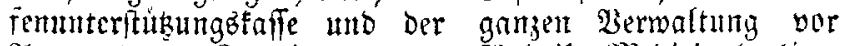

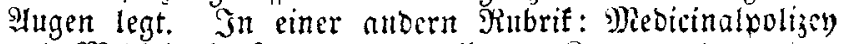

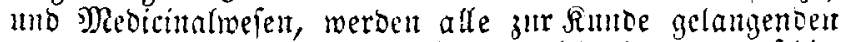

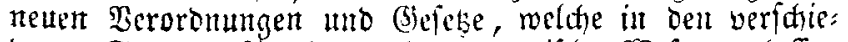
Denen Stanten für ons pbarmaceltilige Beren erlaffen

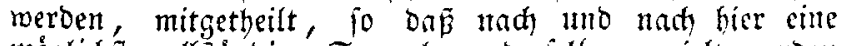
móglitifít volfituntoige Sammlung Derjelben erjielt weroent

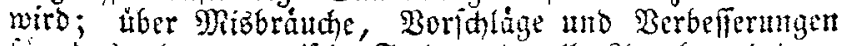
fur bas pharmaceutifhe Fach und alle 2 angelegenteiten, 


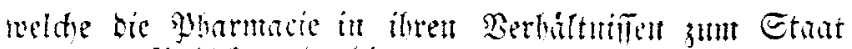
und jum Wubltam Dabietet, werben her Serbandun=

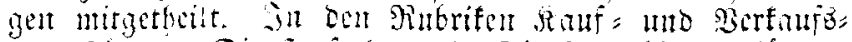
gegemininoe, Sientgeluthe und Sieminaterben finnen

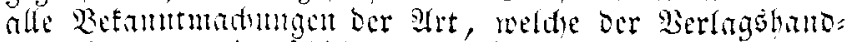

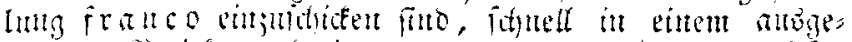

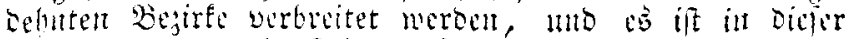

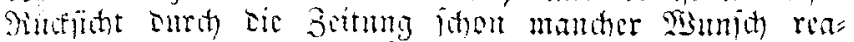

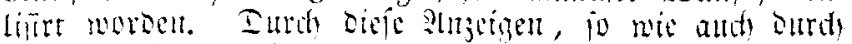

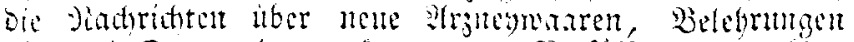

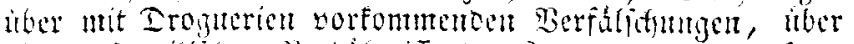

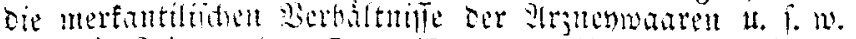

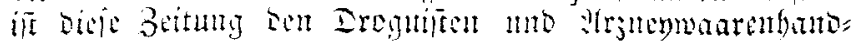

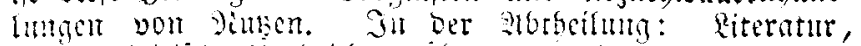

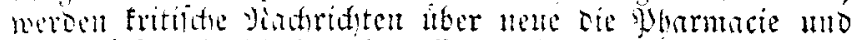

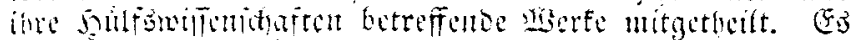

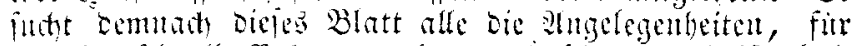

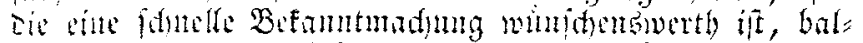

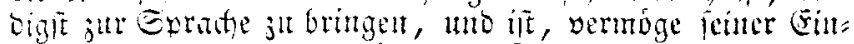
ribtung, saju ganj geeignet. Sndem wir baber bieje

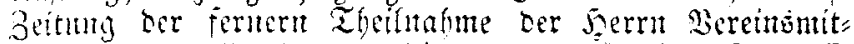
glicer und aller Euten, bie an das juftitut Suterefle

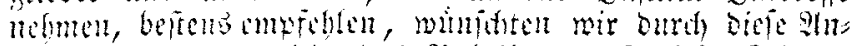
jolge aut merweitig eng Publitum anf bige 3ertmg

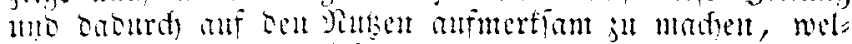

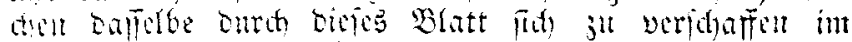

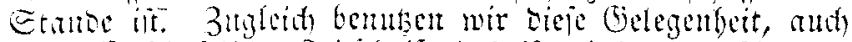

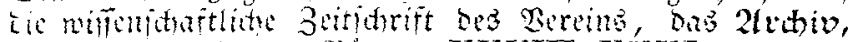
von bent mul in ben Banden XXVIII-XXXI der athte

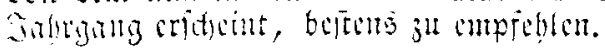

Sene Sorifulogic, vor Sie Eebre won ben (Sjiften und Sergifungen n. f. w.;

Bon bickn in Franfucith mit Beifall aufgenommenen

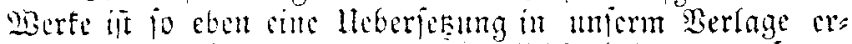

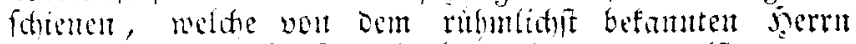
Dr. 2a e firmb in Famelu bearbcitet woroen ift.

Lembo im 刃aำ 1 s29.

\section{Meveride Sovf = Bubblyandung.}

